Mr. Edison, in his telephone and phonograph experiments, discovered that the vibrations of the vocal chords were capable of producing considerable mechanical effect. Acting on this hint, he began experiments on a phonometer, or instrument for measuring the mechanical force of sound-waves produced by the human yoice. In the course of these experiments he constructed the machine shown in Fig. 3, which exhibits the dynamic force of the voice. The machine has a diaphragm and mouth-piece similar to a phonograph. A spring which is secured to the bed piece rests on a piece of rubber tubing placed against the diaphragm. This spring carries a pawl that acts on a ratchet or roughened wheel on the fly-wheel shaft. A sound made in the mouth-piece creates vibrations in the diaphragm, which are sufficient to propel the fly-wheel with considerable velocity. It requires a surprising amount of pressure on the fly-wheel shaft to stop the machine while a continuous sound is made in the mouthpiece.

The speaking trumpet, which, for two centuries at least, has been employed to direct sound so that it may be heard over a long distance, is much used at sea, and is often employed on land to direct vocal sounds so that they may be heard above other sounds. It is tolerably certain that the speaking trumpet is of modern origin, and that it is the invention of Samuel Moreland, 1670 .

Kircher, in his "Ars Magna et Umbra" and in his "Phonurgia," mentions a kind of gigantic speakingtrumpet, described as the horn of Alexander. According to Kircher, this horn enabled Alexander the Great to all his soldiers from a distance of ten miles. The diameter of the ring must have been eight feet, and Kircher conjectures that it was mounted on three poles.

Late in the last century Prof. Huth, a German, made a model of the horn, and found that it served as a powerful speaking-trumpet, but we are considerably in doubt as to the distance through which sounds can be projected through such an instrument.

The ear-trumpet, which is the counterpart of the speaking-trumpet, has been made in various forms during the last two centuries, but no form yet devised has any

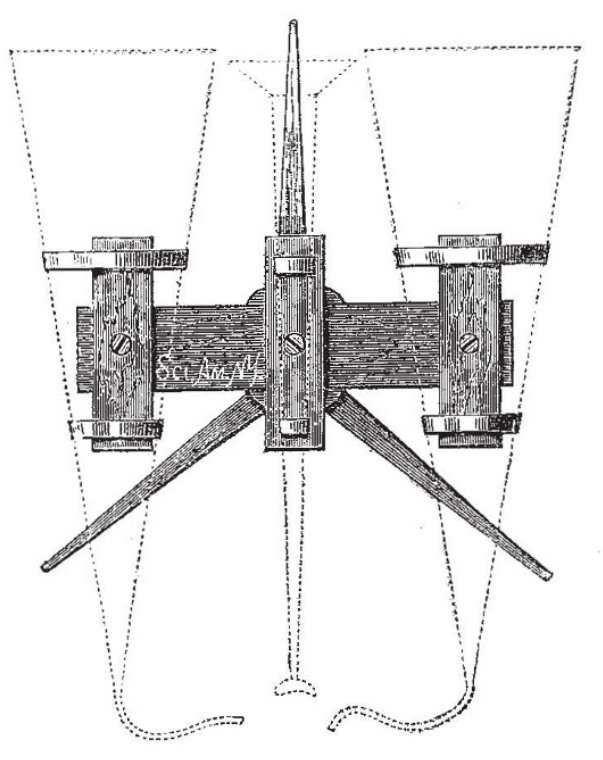

Fig. 4.-Plan of Megaphone.

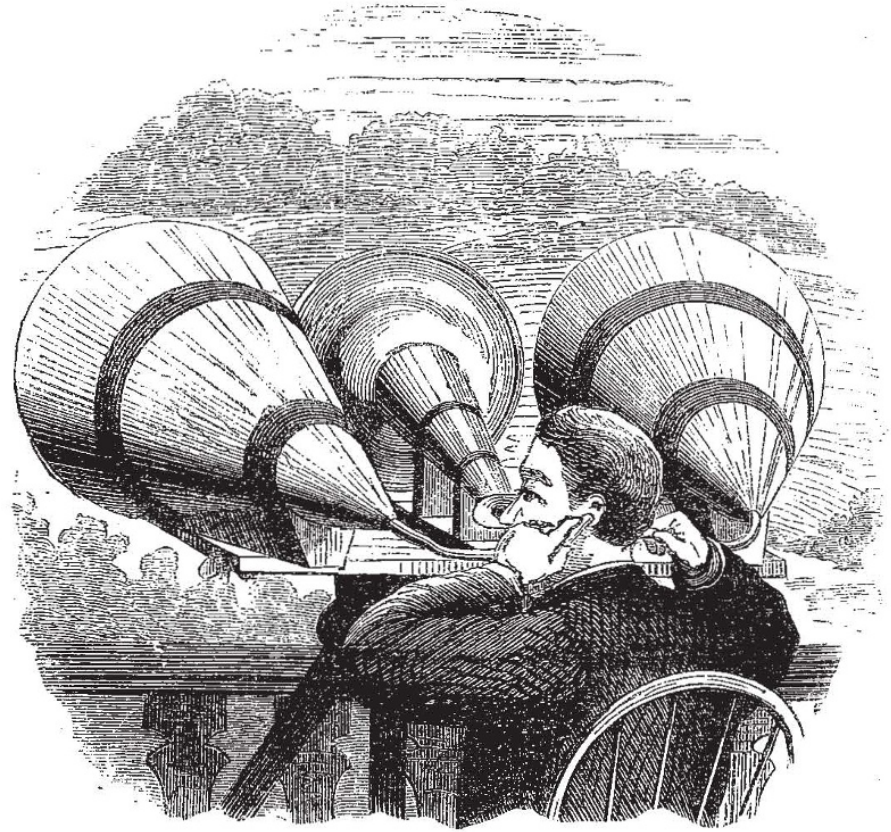

FIG. 5.--Edison's Megaph sne. advantage over a plain conical tube with a bell-sbaped or flaring mouth.

Mr. Edison, in his researches on sound, has made many curious experiments, one of the most interesting of which is that of conversing through a distance of $1 \frac{1}{2}$ to 2 miles with no other apparatus than a few paper funnels. These funnels constitute the megaphone, an instrument wonderful both for its simplicity and effectiveness. In the plan, Fig. 4, the details of construction are clearly shown, and Fig. 5 represents the instrument as it stands on the balcony of Mr. Edison's laboratory. A mile and a half distant there is another instrument exactly like the one in Fig. 5 .

The two larger funnels are 6 feet 8 inches long and $27 \frac{1}{2}$ inches in diameter at the larger end. These funnels are each provided with a flexible ear-tube, the end of which is placed in the ear. The speaking-trumpet in the middle does not differ materially from the ordinary ones. It is a little longer and has a larger bell mouth. With this instrument conversation can be readily carried on through a distance of $1 \frac{1}{2}$ to 2 miles. A low whisper, uttered with- out using the speaking-trumpet, is distinctly audible at a thousand feet, and walking through grass and weeds may be heard at a much greater distance.

These statements, it must be understood, are given on the authority of the Scientific American, but some experiments lately made with a paper megaphone by Prof. Barrett lend them strong support

\section{COLOUR BLINDNESS IN RELATION TO THE HOMERIC EXPRESSIONS FOR COLOUR}

I $N$ an article on "The Colour Sense" in the number of the Nineteenth Century for October last, Mr. Gladstone points out certain peculiarities, very remarkable and very difficult to account for, in the expressions for colour used by Homer. "Although," he says, "this writer has used light in its various forms for his purposes with perhaps greater splendour and effect than any other poet, yet the colour adjectives and colour descriptions of the poems are not only imperiect but highly 
ambiguous and confused," And again-"We find that his sense of colour was not only narrow, but also vague, and wanting in discrimination."

The article is an expansion of a chapter in the same author's "Studies on Homer and the Homeric Age," published in 1858 (vol. iii. page 457), from which the proposition is quoted; " That Homer's perception of the prismatic colours, or colours of the rainbow, and $a$ fortiori of their compounds, were, as a general rule, vague and indeterminate." Mr. Gladstone gives many examples illustrating these opinions, and by powerful and ingenious reasoning, be endeavours to establish from them the general conclusion that "the organ of colour was but partially developed among the Greeks of the heroic age."

I have no intention of disputing this conclusion, in favour of which no doubt much may be said, but I think it may be worth while, on scientific grounds, to point out how remarkably the anomalies and imperfections in question correspond with those that might be expected to arise if the writer were assumed to be colour blind.

Mr. Gladstone makes some allusion to the possibility of a defect in the poet's organisation; but it appears to me that, probably from the facts connected with colour blindness not being fully known to him, he hardly gives this point the attention it deserves. In his earlier essay he expresses the opinion that such a supposition "cannot be resorted to, when we bear in mind Homer's intense feeling for form, and when we observe his effective and powerful handling of the ideas of light and dark." From this remark it is clear that Mr. Gladstone was unaware of the fact that colour blindness can, and usually does, coexist with a perfect feeling for form, and with as vivid ideas of light and dark as are possessed by the normaleyed. In the later article he mentions the defect more specifically, and refers to Prof. Wilson's book on the subject (published in 1855), but he does not add anything to the argument, and appears to leave the point still open to discussion, when further data can be supplied.

In 1856 I presented to the Royal Society a paper on Colour Blindness, which was afterwards published in the Philosophical Transactions, vol. I49, p. 323. Its object was to state my own case (which happens to be one of the most decided on record) and to show that the general phenomena attending this defect of vision were more simple, uniform, and consistent than was generally supposed.

Before I wrote that paper the general impression was that, although there were certain broad particulars in which the sensations of different colour-blind patients agreed, yet there were many varieties of the defect, differing much in character as well as in severity, each being denoted by its own peculiar symptoms, and each, therefore, requiring special classification. Prof, Elie Wartmann, of Lausanne, whose paper on the subject was published in England in 1846 , held the opinion that there were as many varieties of the defect as of individuals affected with it, so that no classification was possible. Dr. Wilson did not go so far as this, but he considered the cases as varying much in degree, and he inclined strongly to the opinion that the most severe form of the defect was very rare.

To illustrate the great variety of mistakes made by the colour blind, and to show the confusion resulting therefrom, I gave the following list of "symptoms" which had been observed in various patients, and which were all combined in my own case:-

Blue and yellow are always perfectly distinguished, even in their lighter or darker tones, and are never confounded with each other.

Only these two colours are seen in the solat spectrum, the blue corresponding to the more and the yellow to the less refrangible rays. The red space is seen as yellow.
Red, though frequently identified in certain cases, is often confounded with black, white, or grey, with orange, with yellow, with green, with brown, with blue, and with violet. Crimson and pink have no relation to the red of vermilion,

Green is a colotr most perplexing to the patient, who camnot be said generally to manifest any definite sensation about it at all. It is confounded not only with red, but also with black, white, or grey, with orange, with yellow, with blue, with violet, and with brown.

Orange is confounded with'yellow; violet is confounded with black or grey, and with blue.

No wonder that philosophers should have despaired of finding any reasonably simple diagnosis for such a heterogeneous mass of symptoms; it was, however, my object to show this could be done. By a long and careful study of my own sensations, aided by a masterly suggestion of Sir John Herschel's that had been published shortly before, I found, in the first place, that notwithstanding the apparent variety of the symptoms in different persons, the defect was uniform, or nearly so, in all; and in the second place, that in spite of the apparent complexity of the phenomena, this defect was of a very simple character. I believe the explanations. I gave have been generally accepted, and subsequent experience has amply confirmed them.

As few people have"a clear understanding what Colour Blindness really means, and as without such an understanding it would be impossible to make my remarks intelligible, I must ask leave to describe the defect as briefly as I can, referring to the Philosophical Transactions for fuller details and demonstrations.

In the first place we see white and black, and their intermediate or compound grey (provided they are free from alloy with other colours), precisely as others do.

Secondly, there are two colours properly so called, namely, yellow and blue, which also, if unalloyed, we see, so far as can be ascertained, in the normal manner.

But these two are the only colours of which we have any sensation; and hence the defect has been given by Sir John Herschel the scientific name of dichromic vision.

But now comes the difficulty of the explanation. It may naturally be asked: Do we not see objects of other colours, such as roses, grass, violets, oranges, and so on? And if we do see them, what do they look like? The answer is that we do see all such things, but that they do not give us the colour sensations correctly belonging to them; their colours appear to us varieties of the other colour sensations which we are able to receive.

This will be best explained by examples. Take first the colour red. A soldier's coat or a stick of red sealingwax conveys to me a very positive sensation of colour, by which I am perfectly able to identify, in a great number of instances, bodies of this hue. If, therefore, the investigation of my experience ended here, there would be no reason to consider me blind to red, or as having any grave defect in my vision regarding it. But when I examine more closely what $I$ really do see, $I$ am obliged to come to the conclusion that the sensation I perceive is not one that I can identify separately, but is simply a modification of one of my other sensations, namely, yellow. It is, in fact, a yellow shaded with black or greya darkened yellow, or what I may call yellow brown. I find that all the most common hues of red correspond with this description, and in proportion as they are more scarlet or more tending towards orange, the yellow I see is more vivid. The explanation, I suppose, is, that none of such reds are pure, they are combinations of red with yellow; so that $I$ see the yellow element of the combination, while the true red element is invisible to me as a colour, and acts only as a darkening shade.

I obtain a further proof of this by the change of sensation when the hue of red is altered. I find that as the colour approaches crimson the yellow element becomes fainter and the darkening shade more powerful, until very 
soon the yellow disappears, and nothing but a grey or colourless hue is presented to my eye, although the colour is still a positive and powerful red to the normal-eyed. So that there is a hue of red which as a colour is absolutely invisible to the colour-blind.

If $I$ go on beyond this point and take reds that pass from crimson towards the hue called lake, I see my other colour come in, a faint blue, which increases till violet is reached, when it becomes more decided.

Violet is understood, I believe, to be a compound of blue with red, and accordingly, the red element being invisible to the colour-blind, violet hues generally appear to them only as darkened blue. There are, however, examples where, from the red being very strong, the blue appears to lose its effect, and the impression given is colourless, black, or grey. They correspond, in fact, with the neutral red before described, although still called violet or purple by the normal-eyed. This latter effect is much enhanced under the artificial light of gas or candles.

A similar explanation will apply to orange, a combination of red and yellow, in which the yellow only is perceived.

The appearance of green to the colour-blind corresponds exactly to that of red; green in its true aspect is invisible to them, and consequently when neutrál, i.e., unmixed with any other colour, it presents to their eyes he appearance of grey: When, however, it is mixed with yellow (and most of the greens in nature are yellow greens) they see the yellow only, but diluted or darkened by the invisible green element. And in the less frequent cases where the green is mixed with blue, they see the blue only; in like manner.

It may now easily be understood how it is that so simple 2 defect of vision gives rise to so complex a series of symptoms as those already described.

Take first the colour red. If it is a scarlet variety, as the majority of reds are, presenting the appearance of yellow to the colour blind, they may naturally confound it with the latter colour, as well as with orange, with yellow green, and with brown, all which cause to them the same sensation. If, on the other hand, the red contains a predominance of blue, it may be confounded, on the same principle, with blue or violet. If it is a neutral red, lying between the two, it will be confounded with black or grey. A pale pink, though very distinctly coloured to the normal-eyed, often offers so little colour to the colour-blind as to be mistaken for white, or very light grey.

The same explanation will apply to green. Its yellow varieties may be confounded with red, orange, yellow, and brown, its blue varieties with blue and violet, and its neutral hue with black or grey, or if very pale, with white.

The confusion of orange with yellow, and of violet with blue, black, and grey, have been already sufficiently explained.

I must now go on to show how the hypothesis of Colour Blindness may serve to explain or account for the anomalies in Homer's descriptions of colour. It is out of my province to meddle with any questions of classical scholarship, I adopt all Mr. Gladstone's critical nterpretations, and I suppose I need not desire a higher authority. It will be convenient to refer to his two essays indiscriminately, using the letter N. for the article in the Nineteenth Century, and $\mathrm{H}$. for the chapter in the Studies on Homer.

Before going into any detail I may notice the general classification which Mr. Gladstone (H. 458, \&c.) has given of the Homeric peculiarities, and it is impossible not to see, at a glance, how exactly this corresponds with what might be expected from the colour-blind.
1. The paucity of Homer's colours. Excluding black and white, Mr. Gladstone reduces them to four, intimating, however, in the following sentence, that even this number is too many.

The colour-blind list is limited to two.

II. The use of the same word to denote not only different hues or tints of the same colour, but colours which, according to the normal-eyed, are essentially different.

This is the shibboleth of the colour-blind defect.

III. The description of the same object under epithets of colour fundamentally disagreeing one from the other.

Mr. Gladstone only names three instances, referring to iron, to the dragon, and to a thunderbolt, none of which appear to me to be very conclusive; but since a colour-blind person may, with perfect correctness according to his own sensations, describe grass as either green, red, orange, or yellow, the defect will amply account for this peculiarity.

IV. The vast predominance of black and white; and

$V$. The slight use of colour, as compared with other elements of beauty for the purpose of poetic effect, and its absence in certain cases where we might confidently expect to find it.

Nothing can be more natural than this, in the case of a writer to whom the great mass of colours in nature are invisible.

When we go into detail, and review the instances Mr. Gladstone has given of Homer's particular applications of colour adjectives, the correspondence with the colourblind hypothesis becomes much closer and more conclusive.

As a general preliminary, let us ask what such a writer, if colour-blind, might be expected to do? How would he be likely to use his epithets of colour?

In the first place he would be certain to use them incorrectly, that is, in a way not consistent with the ideas ordinarily attached to them. He must adopt words in ordinary use; but he can form no proper idea of their meaning, and, as the objects they apply to appear under totally different aspects to him, his use of the words must necessarily be confused and often inappropriate. This may be particularly looked for in regard to red and green; terms which, although conveying ideas so positive and unmistakable to the normal-eyed, have to the colourblind no definite signification at all.

But secondly, there ought to be a certain consistency and intelligibility in his use of the terms when viewed in regard to his own sensations; and if my view of the simple and uniform character of the disease be correct, we ought to be able, knowing what these sensations are, to form a tolerable idea how colour epithets would be applied so as to accord with them.

Omitting all considerations of white, black, or grey, and confining ourselves to colour proper, we know that every coloured object in nature presents to the colourblind person one of two sensations, either that of yellow or that of blue, modified in tone or shade, as I have described. These are positively distinct from each other, and are never confounded. We therefore ought to expect that the colour-epithets used by such a person should be found capable of being arranged in two groups or classes, one corresponding to the yellow sensation, the other to the blue sensation. The various words in either group may have very different meanings to the normaleyed, but if they all convey the same sensation to the colour-blind person, he may be expected to use them indiscriminately. And, moreover, he ought never to apply a word belonging to one class or group, to an object belonging to the other group; if he did he would fail in the consistency to his own sensations which I am now insisting on. For example, if a person applied the word "orange," a word belonging to the yellow group, to lapis lazuli, or the violet flower, which, on the colour-blind 
hypothesis ought to convey to him the idea of blue, the error, although not appearing worse to the normal-eyed than calling grass red, would be altogether inconsistent with the proper colour-blind sensations, and would prove that such a person had not dichromic vision in the sense here intended.'

It may further be remarked that, as the colour-blind person finds the yellow sensation much predominating in what he sees, and as he will have observed that it corresponds to a larger number of ordinary colour-words than the blue sensation, his vocabulary for this group will be naturally more copious than for the opposite one.

(To be continued.) WILLIAM POLE

\section{CHEMICAL NOTES}

Estimation of Mercury.-Prof. Clark, of Cincinnati, describes (Ber. d. deutsch. chem. Gesell. xi. I,409) an interesting application of electrolytic decomposition for the purposes of analytical chemistry, viz., in the separation and estimation of mercury. The solution of the mercury salt, acidulated with sulphuric acid, is placed in a platinum vessel, connected with the zinc pole of a Bunsen bichromate battery of six cells. A piece of platinum foil in connection with the carbon pole is dipped into the liquid, and the decomposition commences at once. At first a mercurous salt is precipitated. This is reduced gradually, until, in the course of an hour, it is completely changed into the metal, which requires simply to be separated from the solution, washed, dried, and weighed. Similar methods for the estimation of zinc, nickel, and copper have for some years been in use.

SEPARATION of ANTIMONy and ARSEnic.--One of the problems in analytical chemistry awaiting solution is a satisfactory separation of arsenic from antimony. In the last number of Liebig's Annalen (vol. 192) Prof. Bunsen presents a new method intended to supersede that hitherto employed, which was discovered by him a number of years since, depending on the treatment of the combined sulphides with sulphurous acid. In the new process the sulphides are dissolved in potash and subjected to the action of chlorine. A quantity of a saturated aqueous solution of sulphuretted hydrogen, sufficient to precipitate the antimony, as $\mathrm{Sb}_{2} \mathrm{~S}_{5}$, is then added, and in the filtrate the arsenic acid is precipitated on heating as $\mathrm{As}_{2} \mathrm{~S}_{5}$ by a long-continued stream of $\mathrm{H}_{2} \mathrm{~S}$.

SPECIFIC Heats of MERCURy aNd IRON.-O. Pettersson and $\mathrm{E}$. Hedelius have recently made careful determinations of the specific heat of mercury and iron in the following manner (Ofzers. f. Vetensk. Förhandl., 37 , p. 35):-A piece of wrought iron was heated in an air bath to $26^{\circ}$, and then plunged in baths containing weighed quantities of mercury fand water at $0^{\circ}$. The resultant temperatures gave the specific heat of iron as referred, firstly to water, and secondly to mercury, and the division of the first value by the second yielded the specific heat of mercury referred to water. The averages derived from twenty experiments give for the average specific heat of wrought iron between $4^{\circ}$ and $27^{\circ}, 0.10808$; and for the specific heat of mercury between $0^{\circ}$ and $5^{\circ}$, 0.033266 . The authors find that the specific heat of mercury suffers but slight alterations between $0^{\circ}$ and $100^{\circ}$.

LATENT Heat of Water at TEMPERATURES BELOW $0^{\circ}$ C.-O. Pettersson (Ofwers. f. Vetensk. Förhandl., 37, p. 53) has lately determined the latent heat of water at temperatures below $0^{\circ}$. For this purpose thin tubes containing water were placed in a mercury calorimeter,

${ }^{1}$ Some errors might, however, legitimately arise in the use of the words for red and green, from the fact that some hues of these colours give yellow sensations, while others give blue sensations. cooled to certain temperatures below $0^{\circ}$, and congelation was induced by the insertion of a snow crystal. The latent heat of water at $0^{\circ}$ according to Regnault is 79.25 . The results obtained by Pettersson at lower temperatures are as follows: $-2.80^{\circ}, 77.71 ;-4.995^{\circ}, 76.60 ;-6.28^{\circ}$, $75^{\circ} 94 ;-6.50^{\circ}, 76^{\circ} 03 ;-6.62^{\circ}, 75^{\circ} 99$; all of them coinciding closely with the estimations of the theoretical formula $\frac{\delta r}{\delta T}=c-h$, where $r$ represents the latent heat of fusion, $T$ the absolute temperature, and $c-h$ the dif ference between the specific heats of the solid and liquid body. Experiments were likewise made with sea water containing 3.536 per cent. of solid matter, and freezing at $-9^{\circ}$. At this temperature pure water would possess a latent heat of 75 ; the sea water possessed on the contrary but 54, showing that the above proportion of saline matter was sufficient to cause a diminution of 28 per cent. in the latent heat.

Preparation of Salts of Nitrous Oxide.-In the Journal of the Chemical Society (clxxxix.) Mr. A. E. Menké describes some of the above salts. In analysing a sample of cast iron an experiment was made attempting the conversion of the phosphorus contained in it by fusion with nitre and sodium carbonate, into an alkaline phosphate. During the operation a bulky yellow precipitate was obtained which proved to be, not a phosphate, but identical with the body obtained by Dr. Divers in the action of sodium amalgam on sodium nitrate. The analysis of the silver salt gave a mean percentage of 78.09 Ag, agreeing therefore with the formula AgNO, which requires 78.26 per cent. Ag. The salt may also be obtained by the simple fusion of iron filings with nitre, the best heat to employ being that of a charcoal furnace. The analysis of the sodium salt obtained by the fusion of iron filings with sodium nitrate gave numbers closely agreeing with the formula $\mathrm{NaNO}+{ }_{3} \mathrm{H}_{2} \mathrm{O}$. The substitution of zinc for iron filings failed to produce the body. On acting on the silver salt with ethyl iodide the silver is converted into iodide, and on fractionating the distillate evidence of the formation of an ethereal salt of low boiling point is obtained.

ON Manganese Tetrachloride $\left(\mathrm{MnCl}_{4}\right)$ - - Some doubt still existing with regard to the decomposition of manganese oxides higher than the dioxide $\mathrm{MnO}_{2}, \mathrm{Mr}$. W. Fisher has recently made experiments bearing upon this point. The oxides employed are the sesquioxide, $\mathrm{Mn}_{2} \mathrm{O}_{3}$, and the red oxide of manganese, $\mathrm{Mn}_{3} \mathrm{O}_{4}$. The analyses of the liquids obtained by the action of the acid on the different oxides were made by decomposing the freshly-prepared solutions with potassium iodide, and then titrating the amount of iodine liberated in each case with sodium hyposulphite. From his experiments $\mathrm{Mr}$. Fisher finds that the higher oxides when treated with excess of acid give a brown liquid containing a highly chlorinated manganese compound easily resolved into manganous chloride and free chlorine, and on dilution with water yielding manganese binoxide in both instances. The solutions appear to be identical, probably containing $\mathrm{MnCl}_{4}$ in each. Under the conditions of the experiment the corresponding chlorides, $\mathrm{Mn}_{2} \mathrm{Cl}_{6}$ and $\mathrm{Mn}_{2} \mathrm{Cl}_{8}$, do not appear to be formed from their corresponding oxides, non do they appear as products of the partial dechlorination of the tetrachloride. The action of the acid on the two oxides the author considers may be represented by the formulæ-

$$
\begin{aligned}
& \mathrm{Mn}_{2} \mathrm{O}_{3}+6 \mathrm{HCl}=\mathrm{MnCl}_{2}+\mathrm{MnCl}_{4}+3 \mathrm{H}_{2} \mathrm{O}, \\
& \mathrm{Mn}_{3} \mathrm{O}_{4}+8 \mathrm{HCCl}=2 \mathrm{MnCl}_{2}+\mathrm{MnCl}_{4}+4 \mathrm{H}_{2} \mathrm{O},
\end{aligned}
$$

and as a large excess of acid or alkaline chloride renders $\mathrm{MnCl}_{4}$ more stable, he thinks it probable that this body: may exist in a form analogous to chloroplatinic acid.

SPONTANEOUS IGNITION OF HYDROGEN BY FINELYDIVIDED ZINC.-In dissolving zinc in hydrochloric acid P. W. Hofmann has observed explosions on the surface 